\title{
Recovery in Soccer
}

\section{Part II-Recovery Strategies}

\author{
Mathieu Nédélec · Alan McCall • Chris Carling • \\ Franck Legall · Serge Berthoin · Gregory Dupont
}

Published online: 16 November 2012

(c) Springer International Publishing Switzerland 2012

\begin{abstract}
In the formerly published part I of this two-part review, we examined fatigue after soccer matchplay and recovery kinetics of physical performance, and cognitive, subjective and biological markers. To reduce the magnitude of fatigue and to accelerate the time to fully recover after completion, several recovery strategies are now used in professional soccer teams. During congested fixture schedules, recovery strategies are highly required to alleviate post-match fatigue, and then to regain performance faster and reduce the risk of injury. Fatigue following competition is multifactorial and mainly related to dehydration, glycogen depletion, muscle damage and mental fatigue. Recovery strategies should consequently be targeted against the major causes of fatigue. Strategies reviewed in part II of this article were nutritional intake, cold water immersion, sleeping, active recovery, stretching, compression garments, massage and electrical stimulation. Some strategies such as hydration, diet and sleep are effective in their ability to counteract the fatigue mechanisms. Providing milk drinks to players at the end of competition and a meal containing high-glycaemic index carbohydrate and protein within the hour following the match are effective in replenishing substrate stores and
\end{abstract}

M. Nédélec · A. McCall · F. Legall · S. Berthoin · G. Dupont

Université Lille Nord de France, Lille, France

M. Nédélec · A. McCall - C. Carling · F. Legall · G. Dupont LOSC Lille Métropole Football Club, Camphin-en-Pévèle, France

\section{G. Dupont $(\bowtie)$}

Laboratory of Human Movement Studies,

Artois and Lille 2 Universities, 9 rue de l'Université,

59790 Ronchin, France

e-mail: gregory.dupont@univ-lille2.fr optimizing muscle-damage repair. Sleep is an essential part of recovery management. Sleep disturbance after a match is common and can negatively impact on the recovery process. Cold water immersion is effective during acute periods of match congestion in order to regain performance levels faster and repress the acute inflammatory process. Scientific evidence for other strategies reviewed in their ability to accelerate the return to the initial level of performance is still lacking. These include active recovery, stretching, compression garments, massage and electrical stimulation. While this does not mean that these strategies do not aid the recovery process, the protocols implemented up until now do not significantly accelerate the return to initial levels of performance in comparison with a control condition. In conclusion, scientific evidence to support the use of strategies commonly used during recovery is lacking. Additional research is required in this area in order to help practitioners establish an efficient recovery protocol immediately after matchplay, but also for the following days. Future studies could focus on the chronic effects of recovery strategies, on combinations of recovery protocols and on the effects of recovery strategies inducing an antiinflammatory or a pro-inflammatory response.

\section{Introduction}

In the formerly published part I of this two-part review [1], we reviewed dehydration, glycogen depletion, muscle damage, inflammation, oxidative stress and mental fatigue as potential factors associated with magnitude of fatigue following a soccer match. A recovery strategy involves the implementation of a technique or a combination of techniques in order to accelerate the time to achieve full recovery and potentially reduce the risk of injury $[2,3]$. 
This review summarizes current research that evaluates recovery strategies, using soccer (Association Football) as the main sport of interest. A computerized literature search was performed using PubMed between January 2011 and January 2012. The following keywords were used in different combinations: 'soccer', 'football', 'recovery', 'modality', 'strategy', 'nutrition', 'diet', 'hydration', 'inflammation', 'cryotherapy', 'cold water immersion', 'cold bath', 'contrast therapy', 'sleep', 'active recovery', 'stretching', 'compression garments', 'massage', 'electrical stimulation' and 'electromyostimulation'. All titles and abstracts were carefully read and relevant articles were retrieved for review. In addition, the reference lists from both original and review articles retrieved were also reviewed.

According to Bishop [4], key gaps in the evidence informing sports practice will only be recognized when the sport-science community frequently consults the evidence base for answers [4]. Scientific research guides practice, but practice can also guide research and a survey about the current recovery strategies used in elite soccer was performed in March 2011. Following a literature search using PubMed to establish a complete list of recovery strategies, 32 practitioners in charge of recovery strategies in French professional soccer teams were questioned on the strategies they implemented. The results showed that cold water immersion and contrast water therapy (88\% of teams), active recovery $(81 \%)$, massage $(78 \%)$, stretching $(50 \%)$, compression garments $(22 \%)$ and electrical stimulation $(13 \%)$ were the strategies used. Nutrition and hydration were considered as very effective recovery strategies by $97 \%$ of the practitioners, while sleep was also considered as an effective recovery strategy (95\% of practitioners).

In part II of this review, the advantages and the limits of these recovery strategies are discussed in an attempt to select the most appropriate strategy/ies following a single soccer match and/or a period of match congestion.

\section{Nutritional Strategies}

As presented in part I [1], rehydration, carbohydrate and protein consumption after a match are effective recovery techniques for replenishing water and substrate stores, and optimizing muscle-damage repair. However, guidelines including quantity, timing and composition are required in order to maximize their effectiveness.

After match-induced dehydration ( $\sim 2 \%$ of body mass), research has shown that consumption of a high sodium drink (61 mmol/L) equivalent to $150-200 \%$ of sweat loss is sufficient to attain a state of hyperhydration $6 \mathrm{~h}$ after ingesting the drink [5].

To optimize the resynthesis of muscle glycogen stores, a high glycaemic index (GI) carbohydrate intake at the end of a match is necessary. An intake of $\sim 1.2 \mathrm{~g}$ carbohydrate/ $\mathrm{kg} / \mathrm{h}$ with a high GI immediately after a match, and at 15-60 min intervals for up to $5 \mathrm{~h}$ [6], enables maximum resynthesis of muscle glycogen stores. However, the effect of high-carbohydrate meals with high GI on subsequent soccer-specific performance is still unclear [7]. When a lower amount of carbohydrate is consumed, co-ingestion of protein $(0.4 \mathrm{~g} / \mathrm{kg} / \mathrm{h})$ could be useful to increase post-exercise muscle glycogen-synthesis rates, as it may stimulate insulin secretion, glucose uptake and muscle glycogen synthase [6]. Nevertheless, Gunnarsson et al. [8] failed to find an increase in glycogen resynthesis $48 \mathrm{~h}$ after a soccer match following ingestion of a whey protein and carbohydrate-enriched diet compared with a normal diet. As exercise stimulates muscle protein synthesis and muscle protein breakdown, the absence of protein intake after exercise can lead to a negative net protein balance [9]. Indeed, a positive muscle protein balance is required to repair exercise-induced muscle damage [10], which is common following a soccer match [1]. Protein consumption stimulates muscle protein synthesis [11] necessary for positive muscle protein balance; although, the quantity, type and timing of protein ingestion to maximize postexercise muscle protein synthesis remains a topic for debate, a consumption of $\sim 20 \mathrm{~g}$ milk protein, or an equivalent of $\sim 9 \mathrm{~g}$ essential amino acids, seems to be sufficient to stimulate muscle protein synthesis rates during the first $2 \mathrm{~h}$ of post-exercise recovery [12]. A high-protein diet with branched chain amino acids also positively impacts other factors associated with recovery such as mental performance or sensation of fatigue [13]. The addition of protein to post-exercise carbohydrate feedings can reduce muscle soreness [14, 15] and decrease the creatine kinase (CK) concentration [15-17] and myoglobin concentration $[17,18]$. It can also improve subsequent muscle function $[17,18]$ and cycling performance exercise [16] in comparison with a simple carbohydrate beverage. Following a match, flavoured milk, which is an easily accessible and relatively inexpensive dairy product, could be an effective beverage for post-exercise recovery. It contains carbohydrate and proteins in amounts similar to those used in studies demonstrating improved post-exercise recovery. Numerous studies have confirmed the significant effects of post-exercise chocolate milk supplementation on subsequent exercise performance [17, 19-22], intracellular signalling stimulus for protein synthesis [21], perceived soreness [23], and CK levels [24].

Other studies have found that omega-3 fatty acids, curcumin, tart cherry juice and tomato juice improve the recovery process due to their anti-inflammatory and antioxidant effects. Increased omega-3 concentrations in the blood are associated with decreased levels of proinflammatory markers (interleukin [IL]-6, IL-1ra, tumour necrosis 
factor $[\mathrm{TNF}]-\alpha$, and $\mathrm{C}$-reactive protein [CRP]), and higher levels of anti-inflammatory markers (soluble IL-6r, IL-10, and transforming growth factor [TGF]- $\beta$ ) [25]. Tartibian et al. [26] showed the effectiveness of supplementing subjects during 30 days with $1.8 \mathrm{~g}$ /day omega-3 fatty acids on lower limb soreness $48 \mathrm{~h}$ after eccentric knee extensors exercise. The authors suggested that their findings were due to the anti-inflammatory effects of omega-3 family fatty acids. Nevertheless, evidence of the effectiveness of omega-3 fatty acids in improving physical performance measures post-exercise is lacking [27, 28]. The quantities employed in these studies could be provided in daily food intakes through consumption of a diet rich in $\alpha$-linolenic acid (e.g. linseed oil, rapeseed oil), eicosapentaenoic acid and docosahexaenoic acid omega-3 fatty acids (e.g. salmon, mackerel, anchovies). Curcumin also exhibits anti-inflammatory properties and Davis et al. [29] showed that feeding mice with curcumin $(10 \mathrm{mg})$ daily for 3 consecutive days prior to downhill running significantly offsets the decrement in running performance (i.e. treadmill run time to fatigue, $\mathrm{p}<0.01$; voluntary wheel running activity, $\mathrm{p}<0.05)$ and significantly $(\mathrm{p}<0.05)$ blunted the increase in inflammatory cytokines IL-1 $\beta$, IL-6, TNF- $\alpha$ and CK compared with mice fed with a placebo. Curcumin intake requires further investigation in humans during the postexercise recovery period. Tart cherry juice is also shown to enhance the recovery process. Tart cherries are loaded with antioxidant anthocyanins, which exhibit in vitro antioxidant and anti-inflammatory activities [30]. Connolly et al. [31] demonstrated that a daily dose of $0.682 \mathrm{~L}$ for 4 days prior to and 4 days following eccentric contractions of the elbow flexors reduced muscle soreness and attenuated the loss in muscle force. In an investigation of the efficacy of tart cherry juice consumed before the day of a marathon run and for $48 \mathrm{~h}$ following the run, Howatson et al. [32] showed that the group who ingested the cherry juice recovered isometric strength significantly faster $(\mathrm{p}<0.05)$ and exhibited reduced inflammation (IL-6, $\mathrm{p}<0.001$; CRP, $p<0.01$; uric acid concentrations, $p<0.05)$ and greater total antioxidant status $(\mathrm{p}<0.05)$ compared with the placebo group during recovery. The authors assumed that consumption of the cherry juice may have blunted the secondary muscle damage response, resulting in a more rapid return of strength in the cherry juice group versus placebo. Ramaswamy and Indirani [33] found that $75 \mathrm{~mL}$ of tomato juice (containing $10 \mu \mathrm{g}$ of lycopene) consumed for 60 days after each training session had a beneficial effect on the oxidative stress and on the athletic performance of athletes involved in track events. All of the studies detailed above examining the effectiveness of nutrients on the recovery process have focused on recovery from non-soccer-specific exercises. Thus, the relevance of this evidence in improving recovery between matches in elite soccer players remains to be demonstrated.

It is generally recognized that certain nutrients positively influence the recovery process. In contrast, alcohol consumption can negatively affect a player's ability to recover following exercise. Soccer players occasionally ingest moderate to large volumes of alcohol (ethanol) in the hours after matchplay. Barnes et al. [34] investigated the effects of acute moderate alcohol intake $(1 \mathrm{~g} / \mathrm{kg}$ bodyweight ethanol as vodka and orange juice) on muscular performance during recovery from eccentric exerciseinduced muscle damage. The results showed that peak strength loss at $36 \mathrm{~h}$ post-exercise was significantly greater in the alcoholic beverage condition compared with an isocaloric non-alcoholic beverage condition. A combination of decreased inflammatory response, altered cytokine production and abnormal reactive oxygen intermediate generation after alcohol exposure may hinder the muscle repair and recovery process [35]. To minimize exerciserelated losses in muscle function and accelerate recovery, participants in sports involving frequent eccentric muscle work, such as soccer, should consequently avoid alcoholcontaining beverages in the post-event period [34]. Apart from hindering the muscle repair process, alcohol consumption may also delay the recovery from dehydration [36].

To sum up, evidence suggests that flavoured milk drinks should be given to players at the end of competition. In addition, a meal containing high-GI carbohydrate and protein should be served to players within the hour following play. Their habitual diet should include consumption of omega-3 fatty acids. In addition, tart cherry juice consumed before the match, on the day of the match and on the following days could be provided to the players, especially when two or three matches in 1 week are to be played. We recommend, however, that the effects of systematic consumption of this product on the recovery process should be studied before recommending its chronic consumption. Further research is needed to determine when inflammation should be enhanced or reduced after a soccer match. The outcomes would help to select a nutritional plan in order to increase or decrease the inflammatory response. Currently, the inflammatory process is accentuated at the end of the match by consuming high-GI carbohydrate and protein in order to increase the glycogen stores and muscle function and to decrease muscle soreness. Finally, future studies may investigate if it is necessary to adapt nutritional recovery strategies according to playing position and/or individual activity performed during the match. For example, a spontaneous higher carbohydrate intake is observed for players in a more 'physically' demanding position 
(i.e. fullbacks, midfielders and wingers) compared with goalkeepers and centrebacks [37].

\section{Cold Water Immersion}

The survey on recovery strategies used by professional soccer teams revealed that cold water immersion and contrast water therapy are the most common recovery strategies employed in French professional soccer teams, as these are currently used by $88 \%$ of teams. Cold water immersion performed immediately after exercise and repeated throughout the recovery process [38-42] has proven to be a superior recovery modality when compared with passive recovery, contrast water immersion [41] and hot water immersion [40]. Therefore, this section deals only with cold water immersion. Table 1 presents the effects of cold water immersion on physical performance and on subjective and biological markers following soccerspecific exercise. Cold water (temperature range: $9-10{ }^{\circ} \mathrm{C}$; duration range: $10-20 \mathrm{~min}$ ) immersion post-exercise provided worthwhile beneficial effects on anaerobic performances, i.e. maximal strength $[38,41,43,44]$, sprint ability [41] and countermovement jump [45]. Moreover, cold water immersion was beneficial in reducing muscle soreness [38, 41-47] and decreasing CK and myoglobin concentrations [38, 43]. Cold water immersion protocols are generally heterogeneous in terms of temperature, duration and level of immersion [38-42] and the best compromise has yet to be determined. Other cold water immersion protocols (temperature range: $10-15{ }^{\circ} \mathrm{C}$; duration range: $5-15 \mathrm{~min}$ ) were all found to provide beneficial effects on maximal strength [40, 48], sprint ability [39], cycling performance [49] and rowing performance [48], and reduced localized oedema [40]. However, these have not been tested in soccer players. Time (e.g. immediately after the match, delayed several hours after the match, or the day after) and frequency of use are other important issues related to cold water immersion. Work by BrophyWilliams et al. [50] found that running performance on the subsequent day between immediate cold water immersion and delayed cold water immersion trials were similar $(\mathrm{p}=0.147)$, while qualitative analyses demonstrated that immediate cold water immersion resulted in a $79 \%$ likely benefit when compared with delayed cold water immersion. The study demonstrates that cold water immersion immediately after a high-intensity exercise session was more beneficial for next-day running performance than cold water immersion performed $3 \mathrm{~h}$ after the session.

The recovery benefits of cold water immersion are most likely due to water temperature rather than hydrostatic pressure [41, 42]. Full-body immersion in cold water at $15{ }^{\circ} \mathrm{C}$ for 15 min reduces blood flow to the legs and to the arms, inducing a redirection of blood flow from the periphery to the core and thereby improving venous return and cardiac efficiency [49]. Cold water may also reduce acute inflammation from muscle damage [51] and has a short-term analgesic effect related to reduction of nerve conduction velocity, muscle spindle activity, the stretchreflex response and spasticity, thus inhibiting the painspasm cycle [52].

In contrast, cold water immersion following matchplay can present some limitations. Although scientifically unproven, the reduction in skeletal muscle blood flow induced by cold water immersion could, in theory, alter glucose availability to the muscle during recovery and therefore alter the rate of post-exercise glycogen synthesis. Additionally, using cold water immersion on a regular basis may hinder exercise-induced adaptations. Yamane et al. [53] proposed leg endurance training and forearm flexor muscles resistance training 3-4 times a week for 4-6 weeks. Cold-water immersion was applied after each training session to one leg and one arm of subjects, with the other leg and the other arm resting at room temperature. Significant training effects were three times higher in the control group than in the 'cold' group $(\mathrm{p}<0.05)$, including increases in artery diameter in the control group but not in the cold group. The authors proposed partial suppression of heat shock protein induction in the cooled relative to the non-cooled muscles to explain that post-exercise cold water immersion is an adverse treatment from the viewpoint of physical training. Exercise induces heat shock protein expression such as an increase in muscle temperature [54]. As heat shock protein induction in training of elite male rowers depends on exercise intensity and volume $[55,56]$, cooling recovery strategies after each training session should be avoided among elite athletes to allow natural induction of heat shock protein, which is responsible for long-term muscle adaptations. However, the study by Yamane et al. [53] presents several limitations with respect to the present review. Non-athlete subjects exercised at an intensity below the threshold of delayed-onset muscle soreness before immersing their leg for $40 \mathrm{~min}$ in water at $5{ }^{\circ} \mathrm{C}$. This model is unlikely to closely reflect the physical demands of elite soccer players. Moreover, it should not be excluded that the cooled limb recovered better than the control limb during the training programme, making the training stimulus too low to induce any training effect in the cooled limb. In support of these limitations, Howatson et al. [57] found that cold water immersion did not inhibit the repeated bout effect when given four times after the first of two bouts of drop jump exercise separated by 14-21 days.

Generally, cold water immersion is an effective recovery strategy during acute periods of fixture congestion to improve physical performance and reduce muscle soreness. 


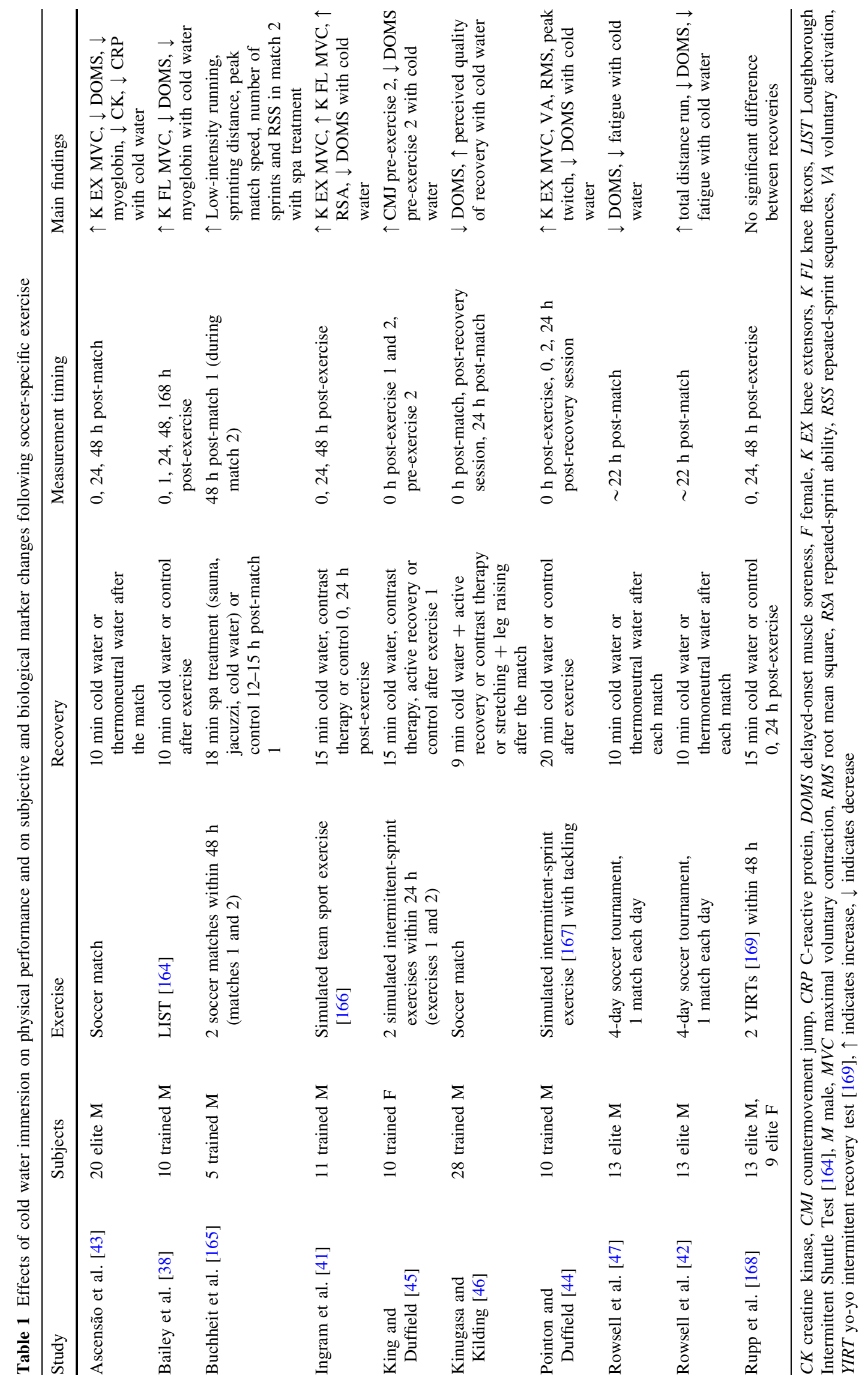


Apart from these periods, and particularly during training periods, it should be avoided to prevent treatment durationdependent interference with the repair and adaptive process [58-60]. Additional studies on anti-inflammatory recovery strategies are necessary to determine the optimal time after exercise to implement the treatment. A biphasic recovery pattern of muscle performance after exercise-inducing muscle damage is reported, i.e. a rapid recovery related to metabolic fatigue subsidence within the first hours after exercise, followed by the second and slow phase of the recovery during subsequent days related to the muscle repair [61-64]. Implementing anti-inflammatory recovery strategies according to the evolution of the inflammatory response may increase their effectiveness.

\section{Sleeping}

Neurometabolic theories of sleep function propose that sleep repays the neural and metabolic cost of waking [65]. Slow-wave sleep, which includes four distinct stages (stages 1, 2, 3 and 4), is characterized by slow breathing, a low heart rate, low cerebral blood flow and a large increase of growth hormone secretion allowing physiological restitution [66]. Both slow-wave sleep and rapid-eye-movement sleep are implicated in the plastic cerebral changes that underlie learning and memory [67-69]. In this respect, the question of sleep in the recovery management should be studied.

When playing an evening soccer match, professional soccer players are subjected to a high physical and mental work load, in addition to high emotional stress. Players must perform at their peak when psychomotor vigilance and subjective alertness tend to decrease after a typical day of activity [70]. Irregular sleep-wake schedules influence the homeostatic and circadian regulation of sleep and, in turn, its quality and quantity [71]. Post-match routines (i.e. medical care, recovery strategies, meals and the return trip) frequently lead to a very late bedtime, which may also alter sleep quality and quantity [72]. Another potential cause of sleep disturbances after a match is waking several times during the night because of hyperhydration [73]. As a result, many players experience a disturbed night's sleep following competition, which can have multiple negative consequences. As extensive sleep loss (i.e. $30 \mathrm{~h}$ of sleep deprivation) is associated with reductions in muscle glycogen content [74], and chronic sleep restriction (i.e. restriction to $50 \%$ of the habitual time over 12 days) may contribute to the amplification of soreness [75], future studies are required to investigate the acute and chronic effects of a disturbed night's sleep after a match among soccer players or over periods of match congestion. In addition to its impact on sleep quantity, a night of sleep loss is also characterized by sleep architecture disturbance. Sallinen et al. [76] found that the proportion of stage 4 sleep is highest in the sleep debt condition but the proportions of stages 1 and 2 sleep are lower during a night of limited sleep than in the normal sleep condition. Additionally, sleep loss may impose a reduction in the ability to commit new experiences to memory [77]. Close connections also exist between sleep and the immune system. Cohen et al. [78] showed that subjects with less than $7 \mathrm{~h}$ of sleep per night in the weeks preceding exposure to a rhinovirus are threefold more likely to develop a cold than those with $8 \mathrm{~h}$ or more of sleep. Partial sleep deprivation (being awake from 11:00 pm to 3:00 am) induces a functional alteration of the monocyte pro-inflammatory cytokine response and alters the expression of pro-inflammatory cytokine genes [79]. In the morning after a night of sleep deprivation, inflammatory responses are enhanced compared with morning levels following uninterrupted sleep [79]. Studies on the link between sleep loss and illness in the elite soccer player are warranted.

To counteract a disturbed night's sleep among soccer players, several factors have been proposed to improve sleep after the match and during the following nights. A high-GI carbohydrate, which is recommended for rapid restoration of muscle glycogen stores [80], may also positively influence sleep. Afaghi et al. [81] showed that a high-GI meal resulted in a significant shortening of sleeponset latency compared with a low-GI meal $(9.0 \mathrm{~min}$ vs. $17.5 \mathrm{~min}$, respectively; $\mathrm{p}<0.01)$ and was most effective when consumed $4 \mathrm{~h}$ before bedtime compared with the same high-GI meal given $1 \mathrm{~h}$ before bedtime $(\mathrm{p}=0.01)$. Sleep initiation depends on a thermophysiological cascade with body heat loss promoting sleepiness and the rapid onset of sleep [82]. Recovery strategies such as cold water immersion reduce body temperature [49], which may consequently promote sleep onset. Other recommendations for sleep induction include benefiting from a dark and quiet environment by using eye shades and ear plugs, listening to relaxing music and adopting regular sleep-wake schedules [83]. Conversely, consumption of caffeine prior to the match for performance enhancement [84], consumption of alcohol as a means of celebrating after the match [85], and hyperhydration [73] potentially lead to sleep disturbance. However, a poor night's sleep may be compensated for by a short post-lunch nap [86, 87]. Waterhouse et al. [87] found that a nap followed by a 30-min recovery period improves alertness and aspects of mental and physical performance following partial sleep loss. The ability to nap for short periods during the day may be a useful skill for players to develop, especially during a congested schedule. Moreover, nocturnal sleep following a night of partial sleep loss should also be promoted during several nights. Sallinen et al. [76] found that, after a night of limited sleep, 
an 8-h recovery sleep opportunity the following night markedly improved both cognitive performance and alertness but did not lead to complete recovery [76]. Finally, resting periods and sleep-wake schedules are normally planned for the entire team, regardless of individual distinctions. Planning individualized schedules based on players' preferred sleep schedules may be another effective countermeasure to restore good sleep [72, 88].

\section{Active Recovery}

Active recovery, also referred to as 'cooling down' or 'warm down', is currently performed by $81 \%$ of French professional soccer teams immediately after the match and/or on the following days. This strategy involves running, biking or swimming at low intensities for a duration of 15-30 min. This recovery strategy is often implemented in professional soccer, as results from numerous studies [89-94] have reported that active recovery, performed between $30 \%$ and $60 \%$ of maximal oxygen consumption and lasting at least $15 \mathrm{~min}$, enhanced blood lactate removal or accelerated $\mathrm{pH}$ recovery $[95,96]$ in comparison with passive recovery. However, lactate removal should not be the criterion used to test the quality of recovery. Faster lactate removal does not necessarily involve better performance during subsequent exercise. In several studies aimed at comparing active and passive recoveries, exercise performance after active recovery did not improve, despite lower lactate concentrations [91, 97, 98], while other studies showed that passive recovery improved performance in subsequent exercise [99-103]. Several studies $[95,104,105]$ have reported that active recovery performed immediately after high-intensity exercises significantly impaired glycogen synthesis, especially in type I muscle fibres [95]. According to these results, active recovery performed immediately after a match does not present a benefit to implement this technique as part of a recovery strategy. However, further studies are required to justify what type of exercise should be performed in the days following a match.

In a set of studies on recovery between two elite female soccer matches separated by 3 days, Andersson et al. [106-108] extensively investigated the effects of 1-h active recovery (submaximal cycling at $60 \%$ heart rate peak and low-intensity resistance training at $<50 \%$ one-repetition maximum) performed at $22 \mathrm{~h}$ and $46 \mathrm{~h}$ after the first match. The results showed that active recovery had no effects on the recovery pattern of physical performance markers (i.e. countermovement jump, $20 \mathrm{~m}$ sprint performance, and maximal isokinetic knee flexion and extension), perceived muscle soreness and biochemical markers (i.e. CK, urea and uric acid) [107]. Andersson et al. [106] did not report any differences in the pro- or in the anti-inflammatory cytokine response between the active recovery group and the passive group. Finally, the active recovery regimen had no effect on changes in oxidative stress markers and antioxidants [108]. According to these results, implementing $1 \mathrm{~h}$ of active recovery during the 3 days following a match does not seem beneficial, nor detrimental to the outcome of the recovery process. Further research on exercise mode, duration and intensity and the time of active recovery is needed to clarify its interest as a recovery modality.

\section{Stretching}

Elite soccer teams devote a substantial amount of training and match preparation time to stretching. Dadebo et al. [109] reported that the English Premiership clubs allocated almost $40 \%$ of total training time to flexibility training with static stretching, the most popular technique employed. The Premiership clubs reported a mean static stretching holding time of $31 \mathrm{~s}$ and a mean number of repetitions per hamstring muscle group of three (range: 2-5) repetitions per session. Stretching exercises are performed for several reasons, including improvement of the range of motion and the decrement of musculotendinous stiffness [110, 111] to prevent injury [109, 112, 113], as well as promoting recovery. In French professional soccer, $50 \%$ of teams currently use stretching as a recovery strategy. However, there is no substantial scientific evidence to support the use of stretching to enhance the post-exercise recovery of soccer players [46, 114, 115]. In a meta-analysis including 12 studies, Herbert et al. [116] reported that stretching is not clinically worthwhile for reducing muscle soreness in the days following exercise. Stretching after eccentric exercise may even hinder the outcome of the recovery process. Lund et al. [117] suggested that both stretching and eccentric exercise leading to delayed onset of muscle soreness may affect the muscle tissue, which may explain the fact that the seven untrained women in their study showed a greater decrease in concentric and eccentric quadriceps strength following both eccentric exercise and stretching in comparison with eccentric exercise alone.

\section{Compression Garments}

Compression garments function by applying a pressure on the lower extremities in order to increase femoral blood flow [118]. The principle is to increase the pressure on the ankle and to decrease it on the mid-thigh in order to improve the venous return and thus reduce venous stasis in the lower extremities [118]. This section will only focus on 
the effects of compression garments on the recovery process. Compression garments, especially for the lower body, have recently become increasingly popular amongst applied soccer practitioners in an attempt to accelerate recovery from training and competition. Twenty-two per cent of French professional soccer teams currently integrate compression garments into their recovery protocol. While studies have shown possible interest in the recovery of muscle soreness to pre-exercise levels, improvements in performance measures post-exercise are lacking. No benefits in repeated-sprint performance [119, 120], peak power output [120], isokinetic strength [121], sprint, agility and countermovement jump performance [122] have been reported with regard to the use of compression garments during the recovery process, although all of these studies reported subjective feelings of recovery improvement when using compression garments. As the studies did not have a placebo condition (i.e. using a garment, but no compression), a placebo effect due to wearing the garments should not be excluded [120].

Up until now, studies demonstrating the potential utility of compression garments for post-exercise recovery have only addressed their use in elderly athletes [123] or untrained subjects $[124,125]$, who are unlikely to closely reflect the demands of elite soccer. With elderly athletes, Chatard et al. [123] found that wearing compression garments during an 80-min recovery period between two maximal 5-min cycling exercises led to a significant $2.1 \%$ increase in subsequent performance. Gill et al. [126] reported effects on post-exercise removal of metabolites: full-leg compression garments, worn for $12 \mathrm{~h}$ after a single rugby match, enhanced CK clearance more than passive recovery in elite male rugby players. However, the ability of compression garments to enhance the overall rate of recovery and especially physical performance after a match is yet to be demonstrated. Another potential limitation of studies on compression garments is that the actual pressures applied by the garments to subjects are not measured [122]. As a consequence, the minimum pressure of $18 \mathrm{mmHg}$ at the ankle and $8 \mathrm{mmHg}$ at the level of the mid-thigh is not always guaranteed [127]. According to Montgomery et al. [39] and Davies et al. [122], the level of compression may be insufficient to have a beneficial impact following normal exercise (i.e. a team sport competitive match); however, after extreme eccentric exercise, compression garments may be effective when disruption to muscle architecture and swelling is more apparent. Trenell et al. [128] reported that $1 \mathrm{~h}$ after eccentric exercise, the leg wearing a compression garment showed a significant elevation $(p<0.05)$ in phosphodiester on phosphorus magnetic resonance spectroscopy spectra relative to the control leg (no compression). Phosphodiester is representative of increased skeletal muscle membrane turnover, and this result suggests an accelerated inflammatory and repair timeframe induced by compression garments.

In conclusion, the use of compression garments following an elite soccer match may be useful to alleviate muscle soreness but more research is required to demonstrate the ergogenic benefits. Compression garments have no additional benefit in comparison with active recovery [126], contrast water therapy [126, 129] or massage [125]. As no studies have reported negative effects on exercise performance, the use of compression garments may provide an easy-to-use recovery strategy in a team. They could be useful during air travel, especially during a long flight, to reduce the risk of deep vein thrombosis [130]. Nevertheless, caution should be taken, as compression garments may be uncomfortable to wear during the night and are associated with an increase in body temperature, thereby disturbing subjects' patterns of sleep [122].

\section{Massage}

Massage corresponds to a 'mechanical manipulation of body tissues with rhythmical pressure and stroking for the purpose of promoting health and well-being' [131]. To promote recovery after a soccer match, numerous techniques such as effleurage, petrissage, tapotement, friction and vibration are currently used in $78 \%$ of French professional soccer teams. Effleurage involves light pressure at the beginning to heavier deeper pressure towards the end and aims to soothe sore muscles and to relax [132]. Petrissage involves a kneading motion where tissue is compressed and lifted away; it aims to loosen muscle spasm [132]. Tapotement consists of repeated rapid hand striking and aims to stimulate muscle tissues [133]. Friction is short deep stroking parallel or transversally across the tissue fibre direction and aims to reduce muscle spasms [132]. Vibration consists of shaking and aims to facilitate muscle relaxation [132]. Expected benefits of massage include both physiological and psychological functions. Pulsed Doppler ultrasound and echo Doppler have been used to investigate muscle blood flow and indicated that manual massageeffleurage, petrissage or tapotement—did not increase blood flow in small (forearm) or large (quadriceps) muscle mass [134-136]. No beneficial effect was found for blood lactate removal [136, 137], $\mathrm{H}^{+}$removal [136] and neutrophil counts [138]. Whilst for physiological function, benefits of massage are still lacking, the scientific evidence supporting their psychological benefits is substantially greater. Weinberg et al. [139] observed a positive relationship between massage and mood state. Two studies [140, 141] found that massage decreased the subjective symptoms of delayedonset muscle soreness. Hemmings et al. [137] investigated the effect of massage on a measure of perceived recovery 
made by the subjects rating their feeling on a 4-item linear scale (refreshed, recharged, rested and recovered) during the 1-h recovery implemented between two simulated boxing bouts. The results showed that massage intervention significantly increased perceptions of recovery compared with the passive rest intervention without improving punching force during the second bout. Similarly, Hilbert et al. [138] found that the intensity of soreness was significantly lower $(\mathrm{p}<0.05)$ in subjects receiving a massage treatment (effleurage, tapotement and petrissage) relative to the control group at $48 \mathrm{~h}$ post-exercise. However, no significant treatment differences for eccentric hamstring peak torque were reported. This latter result confirms that soreness is poorly correlated with changes in muscle function, in terms of both magnitude and time-course after exercise-induced muscle injury [142]. In terms of performance recovery, most of the studies failed to find a significant beneficial effect of massage on subsequent exercise after local exercises [143-146] or global exercises [92, 147]. It should not be excluded that massage of injured tissue may lead to further damage in muscle if given immediately after a training session that induced muscle damage. Viitasalo et al. [148] found that $\mathrm{CK}$ and myoglobin concentrations were significantly higher in elite athletes receiving water massage after strength/power training sessions than during the control week. However, results from our survey suggest that water massage is not a common practice with elite soccer players. The potential effects of effleurage, petrissage, tapotement, friction and vibration in further damaging injured tissue remain, consequently, allusive.

In conclusion, the majority of the evidence points towards massage being effective in alleviating muscle soreness and improving perceptions of recovery, although its effect on muscle function and performance is unclear. The inconsistency in research findings could be attributed to the large variety of massage techniques used and the individual skill of the therapist $[149,150]$. Further research is required to identify the conditions of massage (the type, duration and period) that produce positive benefits for the recovery process.

\section{Electrical Stimulation}

Electrical stimulation is another recovery strategy used by some professional soccer players (13\% of French professional soccer teams). Electrical stimulation involves the transmission of electrical impulses via surface electrodes to peripherally stimulate motor neurons, eliciting muscular contractions [151]. Many electrical stimulation forms can be performed according to the frequency, the intensity or current amplitude, pulse characteristics (the shape and duration), duty cycle, electrode [152]; but transcutaneous electrical nerve stimulation [153] and low-frequency electrical stimulation [154-157] are those most frequently used for recovery purposes [158]. The effects of electrical stimulation on the recovery of strength production capacity and on the reduction of muscle soreness were reviewed by Babault et al. [158]. Results concerning the benefits of electrical stimulation using transcutaneous electrical nerve stimulation or low-frequency electrical stimulation on the recovery process are equivocal. Among studies reviewed by Babault et al. [158], 11 of 12 studies failed to find a significant effect of electrical stimulation on the ability to maintain performance after exercise [153-155, 157, 159-161]. Positive effects of low-frequency electrical stimulation were found for CK clearance [160] and blood lactate removal [161, 162], with the limits previously evoked for these biochemical markers in the recovery process.

To our knowledge, only two studies on electrical stimulation have been conducted so far in a soccer setting [156, 163]. In these studies, no main effect of electrical stimulation was observed on anaerobic performances (i.e. squat jump, countermovement jump, bounce jumping and $10 \mathrm{~m}$ sprint) but electrical stimulation was more beneficial $(\mathrm{p}<0.01)$ than water-aerobic exercises and passive rest for reducing muscle soreness [156, 163].

In conclusion, although electrical stimulation is often used for recovery purposes, no scientific evidence exists regarding its effects to maintain physical performance. The levels of scientific evidence concerning the decrement of subjective rating such as muscle soreness are also limited.

\section{Conclusion}

As mentioned in part I of our review [1], fatigue following a soccer match is multifactorial and related to dehydration, glycogen depletion, muscle damage and mental fatigue. A multitude of recovery strategies are currently implemented in professional soccer clubs to target these causes of fatigue. Recovery strategies aimed at reducing acute inflammation from muscle damage and enhancing its rate of removal are particularly used in professional soccer settings.

Some strategies such as hydration, diet, sleep and cold water immersion are effective, with regard to their ability to counteract the fatigue mechanisms. For dehydration, Shirreffs et al. [5] recommended consuming a high-sodium drink (61 mmol/L) equivalent to $150-200 \%$ of the sweat loss after a match inducing moderate dehydration $(2 \%$ of body mass). Proteins such as milk should be consumed at the end of a match or after a training session leading to muscle damage in order to reduce muscle soreness and to improve subsequent muscle function. A meal containing high-GI carbohydrate and protein should be served to the players within the hour following the match to replenish 
substrate stores and to optimize muscle-damage repair. In addition, some nutrients containing omega- 3 fatty acids and antioxidants should be included in the daily diet to reduce potential muscle soreness and attenuate the loss of muscle force. Sleep is an essential part of recovery management, as sleep disturbances after a match are common and can negatively impact on recovery processes. Adequate sleep allows a reduction in the amplitude of muscle soreness and appears to be an important factor for mental fatigue. For muscle damage, cold water immersion at a temperature between $9{ }^{\circ} \mathrm{C}$ and $10{ }^{\circ} \mathrm{C}$ for $10-20 \mathrm{~min}$ seems useful during acute periods of fixture congestion in order to regain as quickly as possible the initial level of performance and to repress the acute inflammatory process. Further studies should analyse the effects of these recovery strategies on central fatigue. Scientific evidence for the other strategies reviewed, such as active recovery, stretch, compression garments, massage and electrical stimulation, is still lacking in the ability to accelerate the return to initial levels of performance. The lack of evidence, however, does not mean that these strategies do not aid recovery, but means that the protocols implemented until now do not significantly accelerate the return to the initial level of performance in comparison with a control condition.

Many studies examining the efficacy of recovery strategies have focused on recovery in untrained individuals from non-soccer-specific exercise and/or recovery protocols that do not closely reflect the physical demands of elite soccer play. The applicability of these to recovery between matches for elite soccer players is consequently questionable and has yet to be shown. Other potential limitations of studies regarding recovery strategies are that soccer players may respond differently to recovery strategies if they are accustomed, or not, to playing several matches during a congested schedule and the difficulty in implementing a control condition to prevent any placebo effect (e.g. compression garments).

In the survey on recovery in the professional soccer teams, practitioners revealed that different recovery strategies are combined in overall recovery protocols. While the importance of isolating each strategy to determine its effects in future research remains important, it would also be interesting to analyse the potential interactions between the techniques. Longitudinal research protocols should be led to examine the chronic effects of recovery strategies on cellular to molecular adaptations. If a robust pro- and antiinflammatory cytokine response occurs following a single elite soccer match, a dampened anti-inflammatory cytokine response occurs after a second match played within $72 \mathrm{~h}$ [106]. For future studies, it would be rational to determine when to implement anti- or pro-inflammatory recovery protocols according to the inflammatory response.
Acknowledgments No sources of funding were used to assist in the preparation of this review. The authors have no conflicts of interest that are directly relevant to the content of this review.

\section{References}

1. Nédélec M, McCall A, Carling C, et al. Recovery in soccer: part I-post-match fatigue and time course recovery. Sports Med. In press.

2. Ekstrand J, Waldén M, Hägglund M. A congested football calendar and the wellbeing of players: correlation between match exposure of European footballers before the World Cup 2002 and their injuries and performances during that World Cup. Br J Sports Med. 2004;38(4):493-7.

3. Dupont G, Nedelec M, McCall A, et al. Effect of 2 soccer matches in a week on physical performance and injury rate. Am J Sports Med. 2010;38(9):1752-8.

4. Bishop D. An applied research model for the sport sciences. Sports Med. 2008;38(3):253-63.

5. Shirreffs SM, Taylor AJ, Leiper JB, et al. Post-exercise rehydration in man: effects of volume consumed and drink sodium content. Med Sci Sports Exerc. 1996;28(10):1260-71.

6. Jentjens R, Jeukendrup A. Determinants of post-exercise glycogen synthesis during short-term recovery. Sports Med. 2003;33(2): 117-44.

7. Erith S, Williams C, Stevenson E, et al. The effect of high carbohydrate meals with different glycemic indices on recovery of performance during prolonged intermittent high-intensity shuttle running. Int J Sport Nutr Exerc Metab. 2006;16(4): 393-404.

8. Gunnarsson TP, Bendiksen M, Bischoff R, et al. Effect of whey protein- and carbohydrate-enriched diet on glycogen resynthesis during the first $48 \mathrm{~h}$ after a soccer game. Scand J Med Sci Sports. Epub 2011 Nov 23.

9. Bowtell JL, Leese GP, Smith K, et al. Modulation of whole body protein metabolism, during and after exercise, by variation of dietary protein. J Appl Physiol. 1998;85(5):1744-52.

10. Ivy JL. Regulation of muscle glycogen repletion, muscle protein synthesis and repair following exercise. J Sports Sci Med. 2004;3:131-8.

11. Witard OC, Tieland M, Beelen M, et al. Resistance exercise increases postprandial muscle protein synthesis in humans. Med Sci Sports Exerc. 2009;41(1):144-54.

12. Beelen M, Burke LM, Gibala MJ, et al. Nutritional strategies to promote postexercise recovery. Int J Sport Nutr Exerc Metab. 2010;20(6):515-32.

13. Portier H, Chatard JC, Filaire E, et al. Effects of branched-chain amino acids supplementation on physiological and psychological performance during an offshore sailing race. Eur J Appl Physiol. 2008;104(5):787-94.

14. Millard-Stafford M, Warren GL, Thomas LM, et al. Recovery from run training: efficacy of a carbohydrate-protein beverage? Int J Sport Nutr Exerc Metab. 2005;15(6):610-24.

15. Luden ND, Saunders MJ, Todd MK. Postexercise carbohydrateprotein- antioxidant ingestion decreases plasma creatine kinase and muscle soreness. Int J Sport Nutr Exerc Metab. 2007;17(1): 109-23.

16. Saunders MJ, Kane MD, Todd MK. Effects of a carbohydrateprotein beverage on cycling endurance and muscle damage. Med Sci Sports Exerc. 2004;36(7):1233-8.

17. Cockburn E, Hayes PR, French DN, et al. Acute milk-based protein-CHO supplementation attenuates exercise-induced muscle damage. Appl Physiol Nutr Metab. 2008;33(4):775-83. 
18. Valentine RJ, Saunders MJ, Todd MK, et al. Influence of carbohydrate-protein beverage on cycling endurance and indices of muscle disruption. Int J Sport Nutr Exerc Metab. 2008;18(4): 363-78.

19. Pritchett K, Bishop P, Pritchett R, et al. Acute effects of chocolate milk and a commercial recovery beverage on postexercise recovery indices and endurance cycling performance. Appl Physiol Nutr Metab. 2009;34(6):1017-22.

20. Thomas K, Morris P, Stevenson E. Improved endurance capacity following chocolate milk consumption compared with 2 commercially available sport drinks. Appl Physiol Nutr Metab. 2009;34(1):78-82.

21. Ferguson-Stegall L, McCleave EL, Ding Z, et al. Postexercise carbohydrate-protein supplementation improves subsequent exercise performance and intracellular signaling for protein synthesis. J Strength Cond Res. 2011;25(5):1210-24.

22. Spaccarotella KJ, Andzel WD. The effects of low fat chocolate milk on postexercise recovery in collegiate athletes. J Strength Cond Res. 2011;25(12):3456-60.

23. McBrier NM, Vairo GL, Bagshaw D, et al. Cocoa-based protein and carbohydrate drink decreases perceived soreness after exhaustive aerobic exercise: a pragmatic preliminary analysis. J Strength Cond Res. 2010;24(8):2203-10.

24. Gilson SF, Saunders MJ, Moran CW, et al. Effects of chocolate milk consumption on markers of muscle recovery following soccer training: a randomized cross-over study. J Int Soc Sports Nutr. 2010;18(7):19.

25. Ferrucci L, Cherubini A, Bandinelli S, et al. Relationship of plasma polyunsaturated fatty acids to circulating inflammatory markers. J Clin Endocrinol Metab. 2006;91(2):439-46.

26. Tartibian B, Maleki BH, Abbasi A. The effects of ingestion of omega-3 fatty acids on perceived pain and external symptoms of delayed onset muscle soreness in untrained men. Clin J Sport Med. 2009;19(2):115-9.

27. Houghton D, Onambele GL. Can a standard dose of eicosapentaenoic acid (EPA) supplementation reduce the symptoms of delayed onset of muscle soreness? J Int Soc Sports Nutr. 2012;9(1):2.

28. Lenn J, Uhl T, Mattacola C, et al. The effects of fish oil and isoflavones on delayed onset muscle soreness. Med Sci Sports Exerc. 2002;34(10):1605-13.

29. Davis JM, Murphy EA, Carmichael MD, et al. Curcumin effects on inflammation and performance recovery following eccentric exercise-induced muscle damage. Am J Physiol Regul Integr Comp Physiol. 2007;292(6):R2168-73.

30. Wang H, Nair MG, Strasburg GM, et al. Antioxidant and antiinflammatory activities of anthocyanins and their aglycon, cyanidin, from tart cherries. J Nat Prod. 1999;62(2):294-6.

31. Connolly DA, McHugh MP, Padilla-Zakour OI, et al. Efficacy of a tart cherry juice blend in preventing the symptoms of muscle damage. Br J Sports Med. 2006;40(8):679-83; discussion 683 .

32. Howatson G, McHugh MP, Hill JA, et al. Influence of tart cherry juice on indices of recovery following marathon running. Scand J Med Sci Sports. 2010;20(6):843-52.

33. Ramaswamy L, Indirani K. Effect of supplementation of tomato juice on the oxidative stress of selected athletes. J Int Soc Sports Nutr. 2011;8(Suppl 1):P21.

34. Barnes MJ, Mündel T, Stannard SR. Acute alcohol consumption aggravates the decline in muscle performance following strenuous eccentric exercise. J Sci Med Sport. 2010;13(1):189-93.

35. Szabo G. Consequences of alcohol consumption on host defence. Alcohol Alcohol. 1999;34(6):830-41.

36. Shirreffs SM, Maughan RJ. Restoration of fluid balance after exercise-induced dehydration: effects of alcohol consumption. J Appl Physiol. 1997;83(4):1152-8.
37. Iglesias-Gutiérrez E, García A, García-Zapico P, et al. Is there a relationship between the playing position of soccer players and their food and macronutrient intake? Appl Physiol Nutr Metab. 2012;37(2):225-32.

38. Bailey DM, Erith SJ, Griffin PJ, et al. Influence of cold-water immersion on indices of muscle damage following prolonged intermittent shuttle running. J Sports Sci. 2007;25(11):1163-70.

39. Montgomery PG, Pyne DB, Hopkins WG, et al. The effect of recovery strategies on physical performance and cumulative fatigue in competitive basketball. J Sports Sci. 2008;26(11):1135-45.

40. Vaile J, Halson S, Gill N, et al. Effect of hydrotherapy on the signs and symptoms of delayed onset muscle soreness [published erratum appears in Eur J Appl Physiol 2008 May, 103(1), pp. 121-2]. Eur J Appl Physiol. 2008;102(4):447-55.

41. Ingram $\mathrm{J}$, Dawson B, Goodman $\mathrm{C}$, et al. Effect of water immersion methods on post-exercise recovery from simulated team sport exercise. J Sci Med Sport. 2009;12(3):417-21.

42. Rowsell GJ, Coutts AJ, Reaburn P, et al. Effect of post-match cold-water immersion on subsequent match running performance in junior soccer players during tournament play. J Sports Sci. 2011;29(1):1-6.

43. Ascensão A, Leite M, Rebelo AN, et al. Effects of cold water immersion on the recovery of physical performance and muscle damage following a one-off soccer match. J Sports Sci. 2011; 29(3):217-25.

44. Pointon M, Duffield R. Cold water immersion recovery after simulated collision sport exercise. Med Sci Sports Exerc. 2012;44(2):206-16.

45. King M, Duffield R. The effects of recovery interventions on consecutive days of intermittent sprint exercise. J Strength Cond Res. 2009;23(6):1795-802.

46. Kinugasa T, Kilding AE. A comparison of post-match recovery strategies in youth soccer players. J Strength Cond Res. 2009; 23(5):1402-7.

47. Rowsell GJ, Coutts AJ, Reaburn P, et al. Effects of cold-water immersion on physical performance between successive matches in high-performance junior male soccer players. J Sports Sci. 2009;27(6):565-73.

48. Pournot H, Bieuzen F, Duffield R, et al. Short term effects of various water immersions on recovery from exhaustive intermittent exercise. Eur J Appl Physiol. 2011;111(7):1287-95.

49. Vaile J, O'Hagan C, Stefanovic B, et al. Effect of cold water immersion on repeated cycling performance and limb blood flow. Br J Sports Med. 2011;45(10):825-9.

50. Brophy-Williams N, Landers G, Wallman K. Effect of immediate and delayed cold water immersion after a high intensity exercise session on subsequent run performance. J Sports Sci Med. 2011;10:665-70.

51. Wilcock IM, Cronin JB, Hing WA. Physiological response to water immersion: a method for sport recovery? Sports Med. 2006;36(9):747-65.

52. Meeusen R, Lievens P. The use of cryotherapy in sports injuries. Sports Med. 1986;3(6):398-414.

53. Yamane M, Teruya H, Nakano M, et al. Post-exercise leg and forearm flexor muscle cooling in humans attenuates endurance and resistance training effects on muscle performance and on circulatory adaptation. Eur J Appl Physiol. 2006;96(5):572-80.

54. Morton JP, Kayani AC, McArdle A, et al. The exercise-induced stress response of skeletal muscle, with specific emphasis on humans. Sports Med. 2009;39(8):643-62.

55. Liu Y, Mayr S, Opitz-Gress A, et al. Human skeletal muscle HSP70 response to training in highly trained rowers. J Appl Physiol. 1999;86(1):101-4.

56. Liu Y, Lormes W, Baur C, et al. Human skeletal muscle HSP70 response to physical training depends on exercise intensity. Int $\mathbf{J}$ Sports Med. 2000;21(5):351-5. 
57. Howatson G, Goodall S, van Someren KA. The influence of cold water immersions on adaptation following a single bout of damaging exercise. Eur J Appl Physiol. 2009;105(4):615-21.

58. Lapointe BM, Frémont $\mathrm{P}$, Côté $\mathrm{CH}$. Adaptation to lengthening contractions is independent of voluntary muscle recruitment but relies on inflammation. Am J Physiol Regul Integr Comp Physiol. 2002;282(1):R323-9.

59. Howatson G, van Someren KA. The prevention and treatment of exercise-induced muscle damage. Sports Med. 2008;38(6): 483-503.

60. Smith C, Kruger MJ, Smith RM, et al. The inflammatory response to skeletal muscle injury: illuminating complexities. Sports Med. 2008;38(11):947-69.

61. Lapointe BM, Frenette J, Côté CH. Lengthening contractioninduced inflammation is linked to secondary damage but devoid of neutrophil invasion. J Appl Physiol. 2002;92(5):1995-2004.

62. Raastad T, Hallén J. Recovery of skeletal muscle contractility after high- and moderate-intensity strength exercise. Eur J Appl Physiol. 2000;82(3):206-14.

63. Raastad T, Risoy BA, Benestad HB, et al. Temporal relation between leukocyte accumulation in muscles and halted recovery 10-20 h after strength exercise. J Appl Physiol. 2003;95(6): 2503-9.

64. Paulsen G, Crameri R, Benestad HB, et al. Time course of leukocyte accumulation in human muscle after eccentric exercise. Med Sci Sports Exerc. 2010;42(1):75-85.

65. Frank MG. The mystery of sleep function: current perspectives and future directions. Rev Neurosci. 2006;17(4):375-92.

66. Akerstedt T, Nilsson PM. Sleep as restitution: an introduction. J Intern Med. 2003;254(1):6-12.

67. Maquet P, Laureys S, Peigneux P, et al. Experience-dependent changes in cerebral activation during human REM sleep. Nat Neurosci. 2000;3(8):831-6.

68. Peigneux P, Laureys S, Fuchs S, et al. Are spatial memories strengthened in the human hippocampus during slow wave sleep? Neuron. 2004;44(3):535-45.

69. Diekelmann S, Born J. The memory function of sleep. Nat Rev Neurosci. 2010;11(2):114-26.

70. Wyatt JK, Ritz-De Cecco A, Czeisler CA, et al. Circadian temperature and melatonin rhythms, sleep, and neurobehavioral function in humans living on a 20-h day. Am J Physiol. 1999; 277(4 Pt 2):R1152-63.

71. Fischer FM, Nagai R, Teixeira LR. Explaining sleep duration in adolescents: the impact of socio-demographic and lifestyle factors and working status. Chronobiol Int. 2008;25(2):359-72.

72. Fietze I, Strauch J, Holzhausen M, et al. Sleep quality in professional ballet dancers. Chronobiol Int. 2009;26(6):1249-62.

73. Halson SL. Nutrition, sleep and recovery. Eur J Sport Sci. 2008;8(2):119-26.

74. Skein M, Duffield R, Edge J, et al. Intermittent-sprint performance and muscle glycogen after $30 \mathrm{~h}$ of sleep deprivation. Med Sci Sports Exerc. 2011;43(7):1301-11.

75. Haack M, Mullington JM. Sustained sleep restriction reduces emotional and physical well-being. Pain. 2005;119(1-3):56-64.

76. Sallinen M, Holm J, Hirvonen K, et al. Recovery of cognitive performance from sleep debt: do a short rest pause and a single recovery night help? Chronobiol Int. 2008;25(2):279-96.

77. Walker MP. Cognitive consequences of sleep and sleep loss. Sleep Med. 2008;9(Suppl 1):S29-34.

78. Cohen S, Doyle WJ, Alper CM, et al. Sleep habits and susceptibility to the common cold. Arch Intern Med. 2009;169(1): 62-7.

79. Irwin MR, Wang M, Campomayor CO, et al. Sleep deprivation and activation of morning levels of cellular and genomic markers of inflammation. Arch Intern Med. 2006;166(16): 1756-62.
80. Conlee RK. Muscle glycogen and exercise endurance: a twentyyear perspective. Exerc Sport Sci Rev. 1987;15:1-28.

81. Afaghi A, O'Connor H, Chow CM. High-glycemic-index carbohydrate meals shorten sleep onset. Am J Clin Nutr. 2007; 85(2):426-30.

82. Kräuchi K. The thermophysiological cascade leading to sleep initiation in relation to phase of entrainment. Sleep Med Rev. 2007;11(6):439-51.

83. Postolache TT, Hung TM, Rosenthal RN, et al. Sports chronobiology consultation: from the lab to the arena. Clin Sports Med. 2005;24(2):415-56, xiv.

84. Roehrs T, Roth T. Caffeine: sleep and daytime sleepiness. Sleep Med Rev. 2008;12(2):153-62.

85. Feige B, Gann H, Brueck R, et al. Effects of alcohol on polysomnographically recorded sleep in healthy subjects. Alcohol Clin Exp Res. 2006;30(9):1527-37.

86. Lagarde D, Batejat D. Some measures to reduce effects of prolonged sleep deprivation. Neurophysiol Clin. 1995;25(6): 376-85.

87. Waterhouse J, Atkinson G, Edwards B, et al. The role of a short post-lunch nap in improving cognitive, motor, and sprint performance in participants with partial sleep deprivation. J Sports Sci. 2007;25(14):1557-66.

88. Samuels C. Sleep, recovery, and performance: the new frontier in high-performance athletics. Neurol Clin. 2008;26(1):169-80; ix $-x$.

89. Belcastro AN, Bonen A. Lactic acid removal rates during controlled and uncontrolled recovery exercise. J Appl Physiol. 1975;39(6):932-6.

90. Bonen A, Belcastro AN. Comparison of self-selected recovery methods on lactic acid removal rates. Med Sci Sports. 1976 Fall; $8(3): 176-8$.

91. Bond V, Adams RG, Tearney RJ, et al. Effects of active and passive recovery on lactate removal and subsequent isokinetic muscle function. J Sports Med Phys Fitness. 1991;31(3):357-61.

92. Gupta S, Goswami A, Sadhukhan AK, et al. Comparative study of lactate removal in short term massage of extremities, active recovery and a passive recovery period after supramaximal exercise sessions. Int J Sports Med. 1996;17(2):106-10.

93. Taoutaou Z, Granier P, Mercier B, et al. Lactate kinetics during passive and partially active recovery in endurance and sprint athletes. Eur J Appl Physiol Occup Physiol. 1996;73(5):465-70.

94. Koizumi K, Fujita Y, Muramatsu S, et al. Active recovery effects on local oxygenation level during intensive cycling bouts. J Sports Sci. 2011;29(9):919-26.

95. Fairchild TJ, Armstrong AA, Rao A, et al. Glycogen synthesis in muscle fibers during active recovery from intense exercise. Med Sci Sports Exerc. 2003;35(4):595-602.

96. Sairyo K, Iwanaga K, Yoshida N, Mishiro T, Terai T, Sasa T, Ikata T. Effects of active recovery under a decreasing work load following intense muscular exercise on intramuscular energy metabolism. Int J Sports Med. 2003;24(3):179-82.

97. Weltman A, Stamford BA, Fulco C. Recovery from maximal effort exercise: lactate disappearance and subsequent performance. J Appl Physiol. 1979;47(4):677-82.

98. Weltman A, Regan JD. Prior exhaustive exercise and subsequent, maximal constant load exercise performance. Int $\mathbf{J}$ Sports Med. 1983;4(3):184-9.

99. Dupont G, Blondel N, Berthoin S. Performance for short intermittent runs: active recovery vs. passive recovery. Eur J Appl Physiol. 2003;89(6):548-54.

100. Dupont G, Moalla W, Guinhouya C, et al. Passive versus active recovery during high-intensity intermittent exercises. Med Sci Sports Exerc. 2004;36(2):302-8.

101. Toubekis AG, Douda HT, Tokmakidis SP. Influence of different rest intervals during active or passive recovery on repeated 
sprint swimming performance. Eur J Appl Physiol. 2005; 93(5-6):694-700.

102. Spencer M, Bishop D, Dawson B, et al. Metabolism and performance in repeated cycle sprints: active versus passive recovery. Med Sci Sports Exerc. 2006;38(8):1492-9.

103. Dupont G, Moalla W, Matran R, et al. Effect of short recovery intensities on the performance during two Wingate tests. Med Sci Sports Exerc. 2007;39(7):1170-6.

104. Bonen A, Ness GW, Belcastro AN, et al. Mild exercise impedes glycogen repletion in muscle. J Appl Physiol. 1985;58(5): 1622-9.

105. Choi D, Cole KJ, Goodpaster BH, et al. Effect of passive and active recovery on the resynthesis of muscle glycogen. Med Sci Sports Exerc. 1994;26(8):992-6.

106. Andersson H, Bøhn SK, Raastad T, et al. Differences in the inflammatory plasma cytokine response following two elite female soccer games separated by a 72 -h recovery. Scand J Med Sci Sports. 2010;20(5):740-7.

107. Andersson H, Raastad T, Nilsson J, et al. Neuromuscular fatigue and recovery in elite female soccer: effects of active recovery. Med Sci Sports Exerc. 2008;40(2):372-80.

108. Andersson H, Karlsen A, Blomhoff R, et al. Active recovery training does not affect the antioxidant response to soccer games in elite female players. Br J Nutr. 2010;104(10):1492-9.

109. Dadebo B, White J, George KP. A survey of flexibility training protocols and hamstring strains in professional football clubs in England [published erratum appears in Br J Sports Med 2004 Dec; 38 (6): 793]. Br J Sports Med. 2004;38(4):388-94.

110. Bandy WD, Irion JM, Briggler M. The effect of time and frequency of static stretching on flexibility of the hamstring muscles. Phys Ther. 1997;77(10):1090-6.

111. Kay AD, Blazevich AJ. Reductions in active plantarflexor moment are significantly correlated with static stretch duration. Eur J Sport Sci. 2008;8(1):41-6.

112. Witvrouw E, Danneels L, Asselman P, et al. Muscle flexibility as a risk factor for developing muscle injuries in male professional soccer players: a prospective study. Am J Sports Med. 2003;31(1):41-6.

113. McHugh MP, Cosgrave $\mathrm{CH}$. To stretch or not to stretch: the role of stretching in injury prevention and performance. Scand J Med Sci Sports. 2010;20(2):169-81.

114. Dawson B, Cow S, Modra S, et al. Effects of immediate postgame recovery procedures on muscle soreness, power and flexiblity levels over the next 48 hours. J Sci Med Sport. 2005; 8(2):210-21.

115. Robey E, Dawson B, Goodman C, et al. Effect of postexercise recovery procedures following strenuous stair-climb running. Res Sports Med. 2009;17(4):245-59.

116. Herbert RD, de Noronha M, Kamper SJ. Stretching to prevent or reduce muscle soreness after exercise. Cochrane Database Syst Rev. 2011;(7):CD004577.

117. Lund H, Vestergaard-Poulsen P, Kanstrup IL, et al. The effect of passive stretching on delayed onset muscle soreness, and other detrimental effects following eccentric exercise. Scand J Med Sci Sports. 1998;8(4):216-21.

118. Sigel B, Edelstein AL, Savitch L, et al. Type of compression for reducing venous stasis: a study of lower extremities during inactive recumbency. Arch Surg. 1975;110(2):171-5.

119. Duffield R, Portus M. Comparison of three types of full-body compression garments on throwing and repeat-sprint performance in cricket players. Br J Sports Med. 2007;41(7):409-14; discussion 414.

120. Duffield R, Edge J, Merrells R, et al. The effects of compression garments on intermittent exercise performance and recovery on consecutive days. Int J Sports Physiol Perform. 2008;3(4):454-68.
121. Duffield R, Cannon J, King M. The effects of compression garments on recovery of muscle performance following highintensity sprint and plyometric exercise. J Sci Med Sport. 2010;13(1):136-40.

122. Davies V, Thompson KG, Cooper SM. The effects of compression garments on recovery. J Strength Cond Res. 2009; 23(6):1786-94.

123. Chatard JC, Atlaoui D, Farjanel J, et al. Elastic stockings, performance and leg pain recovery in 63-year-old sportsmen. Eur $\mathrm{J}$ Appl Physiol. 2004;93(3):347-52.

124. Jakeman JR, Byrne C, Eston RG. Lower limb compression garment improves recovery from exercise-induced muscle damage in young, active females. Eur J Appl Physiol. 2010; 109(6): 1137-44.

125. Jakeman JR, Byrne C, Eston RG. Efficacy of lower limb compression and combined treatment of manual massage and lower limb compression on symptoms of exercise-induced muscle damage in women. J Strength Cond Res. 2010;24(11):3157-65.

126. Gill ND, Beaven CM, Cook C. Effectiveness of post-match recovery strategies in rugby players. Br J Sports Med. 2006; 40(3):260-3.

127. Lawrence D, Kakkar VV. Graduated, static, external compression of the lower limb: a physiological assessment. Br J Surg. 1980;67(2):119-21.

128. Trenell MI, Rooney KB, Sue CM, et al. Compression garments and recovery from eccentric exercise: a 31P-MRS study. J Sports Sci Med. 2006;5:106-14.

129. French DN, Thompson KG, Garland SW, et al. The effects of contrast bathing and compression therapy on muscular performance. Med Sci Sports Exerc. 2008;40(7):1297-306.

130. Bartholomew JR, Schaffer JL, McCormick GF. Air travel and venous thromboembolism: minimizing the risk. Minn Med. 2011;94(6):43-9.

131. Galloway SD, Watt JM. Massage provision by physiotherapists at major athletics events between 1987 and 1998. Br J Sports Med. 2004;38(2):235-6; discussion 237.

132. Weerapong P, Hume PA, Kolt GS. The mechanisms of massage and effects on performance, muscle recovery and injury prevention. Sports Med. 2005;35(3):235-56.

133. Standley RA, Miller MG, Binkley H. Massage's effect on injury, recovery, and performance: a review of techniques and treatment parameters. Strength Cond J. 2010;32(2):64-7.

134. Tiidus PM, Shoemaker JK. Effleurage massage, muscle blood flow and long-term post-exercise strength recovery. Int J Sports Med. 1995;16(7):478-83.

135. Shoemaker JK, Tiidus PM, Mader R. Failure of manual massage to alter limb blood flow: measures by Doppler ultrasound. Med Sci Sports Exerc. 1997;29(5):610-4.

136. Wiltshire EV, Poitras V, Pak M, et al. Massage impairs postexercise muscle blood flow and "lactic acid" removal. Med Sci Sports Exerc. 2010;42(6):1062-71.

137. Hemmings B, Smith M, Graydon J, et al. Effects of massage on physiological restoration, perceived recovery, and repeated sports performance. Br J Sports Med. 2000;34(2):109-14; discussion 115.

138. Hilbert JE, Sforzo GA, Swensen T. The effects of massage on delayed onset muscle soreness. Br J Sports Med. 2003;37(1): $72-5$.

139. Weinberg R, Jackson A, Kolodny K. The relationship of massage and exercise to mood enhancement. J Sport Psychol. 1998;2:202-11.

140. Farr T, Nottle C, Nosaka K, et al. The effects of therapeutic massage on delayed onset muscle soreness and muscle function following downhill walking. J Sci Med Sport. 2002;5(4): 297-306. 
141. Zainuddin Z, Newton M, Sacco P, et al. Effects of massage on delayed-onset muscle soreness, swelling, and recovery of muscle function. J Athl Train. 2005;40(3):174-80.

142. Warren GL, Lowe DA, Armstrong RB. Measurement tools used in the study of eccentric contraction-induced injury. Sports Med. 1999;27(1):43-59.

143. Hinds T, McEwan I, Perkes J, et al. Effects of massage on limb and skin blood flow after quadriceps exercise. Med Sci Sports Exerc. 2004;36(8):1308-13.

144. Jönhagen S, Ackermann P, Eriksson T, et al. Sports massage after eccentric exercise. Am J Sports Med. 2004;32(6):1499503.

145. Hunter AM, Watt JM, Watt V, et al. Effect of lower limb massage on electromyography and force production of the knee extensors. Br J Sports Med. 2006;40(2):114-8.

146. Barlow A, Clarke R, Johnson N, et al. Effect of massage of the hamstring muscles on selected electromyographic characteristics of biceps femoris during sub-maximal isometric contraction. Int J Sports Med. 2007;28(3):253-6.

147. Robertson A, Watt JM, Galloway SD. Effects of leg massage on recovery from high intensity cycling exercise. Br J Sports Med. 2004;38(2):173-6.

148. Viitasalo JT, Niemelä K, Kaappola R, et al. Warm underwater water-jet massage improves recovery from intense physical exercise. Eur J Appl Physiol Occup Physiol. 1995;71(5):431-8.

149. Moraska A. Sports massage: a comprehensive review. J Sports Med Phys Fitness. 2005;45(3):370-80.

150. Moraska A. Therapist education impacts the massage effect on postrace muscle recovery. Med Sci Sports Exerc. 2007;39(1): 34-7.

151. Barnett A. Using recovery modalities between training sessions in elite athletes: does it help? Sports Med. 2006;36(9):781-96.

152. Seyri KM, Maffiuletti NA. Effect of electromyostimulation training on muscle strength and sports performance. Strength Cond J. 2011;33(1):70-5.

153. Denegar CR, Perrin DH. Effect of transcutaneous electrical nerve stimulation, cold, and a combination treatment on pain, decreased range of motion, and strength loss associated with delayed onset muscle soreness. J Athl Train. 1992;27(3):200-6.

154. Lattier G, Millet GY, Martin A, et al. Fatigue and recovery after high-intensity exercise. Part II: recovery interventions. Int J Sports Med. 2004;25(7):509-15.

155. Martin V, Millet GY, Lattier G, et al. Effects of recovery modes after knee extensor muscles eccentric contractions. Med Sci Sports Exerc. 2004;36(11):1907-15.
156. Tessitore A, Meeusen R, Pagano R, et al. Effectiveness of active versus passive recovery strategies after futsal games. J Strength Cond Res. 2008;22(5):1402-12.

157. Cortis C, Tessitore A, D'Artibale E, et al. Effects of postexercise recovery interventions on physiological, psychological, and performance parameters. Int J Sports Med. 2010;31(5): 327-35.

158. Babault N, Cometti C, Maffiuletti NA, et al. Does electrical stimulation enhance post-exercise performance recovery? Eur $\mathbf{J}$ Appl Physiol. 2011;111(10):2501-7.

159. Butterfield DL, Draper DO, Ricard MD, et al. The effects of high-volt pulsed current electrical stimulation on delayed-onset muscle soreness. J Athl Train. 1997;32(1):15-20.

160. Vanderthommen M, Soltani K, Maquet D, et al. Does neuromuscular electrical stimulation influence muscle recovery after maximal isokinetic exercise? Isokinetics Exerc Sci. 2007;15:1 43-9.

161. Heyman E, DE Geus B, Mertens I, et al. Effects of four recovery methods on repeated maximal rock climbing performance. Med Sci Sports Exerc. 2009;41(6):1303-10.

162. Neric FB, Beam WC, Brown LE, et al. Comparison of swim recovery and muscle stimulation on lactate removal after sprint swimming. J Strength Cond Res. 2009;23(9):2560-7.

163. Tessitore A, Meeusen R, Cortis C, et al. Effects of different recovery interventions on anaerobic performances following preseason soccer training. J Strength Cond Res. 2007;21(3): $745-50$.

164. Nicholas CW, Nuttall FE, Williams C. The Loughborough Intermittent Shuttle Test: a field test that simulates the activity pattern of soccer. J Sports Sci. 2000;18(2):97-104.

165. Buchheit M, Horobeanu C, Mendez-Villanueva A, et al. Effects of age and spa treatment on match running performance over two consecutive games in highly trained young soccer players. J Sports Sci. 2011;29(6):591-8.

166. Bishop D, Spencer M, Duffield R, et al. The validity of a repeated sprint ability test. J Sci Med Sport. 2001;4(1):19-29.

167. Duffield R, Marino FE. Effects of pre-cooling procedures on intermittent-sprint exercise performance in warm conditions. Eur J Appl Physiol. 2007;100(6):727-35.

168. Rupp KA, Selkow NM, Parente WR, et al. The effect of cold water immersion on 48-hour performance testing in collegiate soccer players. J Strength Cond Res. 2012;26(8):2043-50.

169. Bangsbo J. Yo-yo tests. Copenhagen: AK Institute; 1996. 